\title{
Situs Inversus with Levocardia and Congenitally Corrected Transposition of Great Vessels in a 35 year old Male: A Case report
}

Atefeh Ghorbnazadeh ${ }^{1}$, Nahid Zirak ${ }^{2}$, Afsoon Fazlinezhad ${ }^{3}$, Aliasghar Moenipour ${ }^{4}$, Hamid Hoseinikhah Manshadi ${ }^{4}$, Mohammad Abbasi Teshnizi ${ }^{5}$

${ }^{1}$ Medical Student, Student Research Committee, Mashhad University of Medical Science, Mashhad, Iran

${ }^{2}$ M.D., Associate Professor, Department of Anesthesiology, Faculty of Medicine, Imam Reza Hospital, Mashhad University of Medical Science, Mashhad, Iran

${ }^{3}$ M.D., Associate professor, Department of Cardiology, Faculty of Medicine, Ghaem Hospital, Mashhad University of Medical Science, Mashhad, Iran

${ }^{4}$ M.D., Assistant Professor, Department of Cardiac Surgery, Faculty of Medicine, Imam Reza Hospital, Mashhad University of Medical Science, Mashhad, Iran

${ }^{5}$ M.D., Associate Professor, Department of Cardiac Surgery, Faculty of Medicine, Imam Reza Hospital, Mashhad University of Medical Science, Mashhad, Iran

\section{Type of article: Case report}

\begin{abstract}
Situs inversus with levocardia and congenitally corrected transposition of the great arteries represents a relatively very rare congenital condition and most patients are diagnosed in infancy or early age. This case report describes a 35-year old man with congenitally corrected transposition of the great arteries which presented with a five month history of exertional dyspnea. A diagnosis was confirmed by transesophageal echocardiogram, showing situs inversus, levocardia, atrioventricular and ventriculoarterial discordance. He underwent physiologic repair, and was discharged thirty five days after the operation, in a good general condition. Although management of the corrected transposition of the great arteries patients remains controversial, the recommendation is that physiologic repair may be the procedure of choice for some patients, particularly complicated cases.
\end{abstract}

Keywords: Congenitally Corrected, Levocardia, Situs Inversus

\section{Introduction}

Congenitally corrected transposition of the great arteries (CCTGA) is a rare cardiac anomaly which is characterized by atrioventricular (AV) and ventriculoarterial discordance (transposition of the great arteries), representing less than one percent of all congenital cardiac diseases (1-3). Associated cardiac anomalies are common with CCTGA and seen in eighty percent of all cases (4). The most relevant common associations are ventricular septal defect (VSD), pulmonary stenosis (PS), left AV valve (morphological tricuspid valve) regurgitation and complete heart block (2-4). CCTGA may present as situs solitus or situs inversus (5). In situs solitus, the morphologic right ventricle (mRV) and right atrium (RA) are located on the left and right side, respectively. On the other hand, situs inversus is characterized by the mirror-image location of the thoracic and abdominal organs. Levocardia usually exists in which the cardiac apex is directed to the left. The majority of these patients suffer from situs solitus, and only around thirty four percent of cases have situs inversus (5). Indication for surgery is also determined by the nature and severity of associated cardiac lesions (3). Herein, we present a rare case of an adult with CCTGA and situs inversus with levocardia which, associated with PS and VSD, is a very rare combination.

\section{Corresponding author:}

Associate Professor Dr. Mohammad Abbasi Teshnizi, Department of Cardiac Surgery, Faculty of Medicine, Imam Reza Hospital, Mashhad University of Medical Science, Mashhad, Iran.

Tel: +98.5138521120, Fax: +98.5138521120, Email: abbasim@mums.ac.ir

Received: June 24, 2016, Accepted: August 14, 2016, Published: January 2017

iThenticate screening: August 02, 2016, English editing: October 12, 2016, Quality control: November 17, 2016

(C) 2017 The Authors. This is an open access article under the terms of the Creative Commons Attribution-NonCommercialNoDerivs License, which permits use and distribution in any medium, provided the original work is properly cited, the use is non-commercial and no modifications or adaptations are made. 


\section{Case presentation}

\subsection{History and clinical presentation}

A thirty five year-old man was admitted to our hospital with a five month history of exertional dyspnea. He was visibly cyanotic and had a Class III Dyspnea. Physical examination revealed an irregular rhythm with heart rate at eighty beats/min, a grade III systolic ejection murmur and blood pressure was 135/90 $\mathrm{mmHg}$ in both arms with normal distal pulses. In addition, distal extremities were cyanotic and had a digital clubbing. Hemoglobin (HB) and hematocrit (HCT) were 21.3, 69.1 respectively.

\subsection{Diagnosis}

Chest X-ray showed a left heart axis, a right-sided gastric bubble below the right diaphragm and left-sided hepatic contour (Figure 1). Cardiac catheterization was performed and vein catheter was passed through femoral venous and entered inferior vena cava (IVC) (placed on left side). The catheter was located in the right-sided mRV. Contrast filled the mRV and flowed right to left across the VSD and filled the pulmonary trunk (Figure 2). Transesophageal echocardiogram (TEE) confirmed the diagnosis, and showed situs inversus, levocardia, AV and ventriculoarterial discordance, and also revealed that the aorta was on the right side, anteriorly located, $u$ and furthermore a sub aortic VSD and severe PS (Figure 3) was also seen.

\subsection{Treatment}

After a median sternotomy was carried out, the superior vena cava (SVC) and IVC were located in a leftward position, also the ascending aorta was located anterior and right to the main pulmonary artery (MPA). Standard cardiopulmonary bypass (CPB) was established with the aorta, bicaval cannulation. Cold cardioplegia was delivered into the aortic root and hypothermia was initiated to a T 32 degrees ${ }^{\circ} \mathrm{C}$. After aortic cross clamping, large sub aortic VSD was closed by Gore-Tex patch via morphologic right atrium (mRA). The process was completed by inserting an external biological valved $25 \mathrm{~mm}$ conduit from the morphologic left ventricle $(\mathrm{mLV})$ to the pulmonary trunk (Figure 4). Weaning off CPB was successful. The patient was transferred to the ICU, he had prolonged intubation due to airway edema and acute respiratory distress syndrome (ARDS). Synchronized intermittent mandatory ventilation (SIMV) was initiated and numerous blood secretions were suctioned.

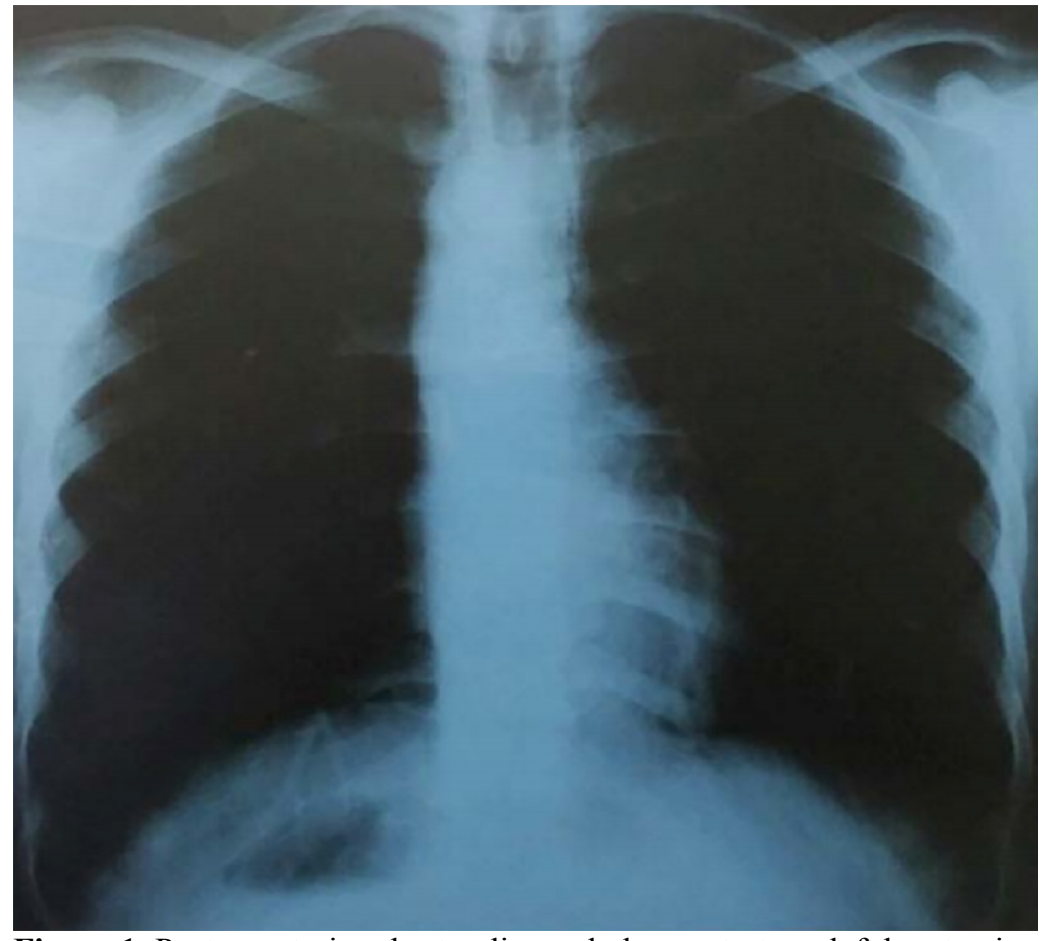

Figure 1. Posteroanterior chest radiograph demonstrates a left heart axis, right-sided gastric bubble. 


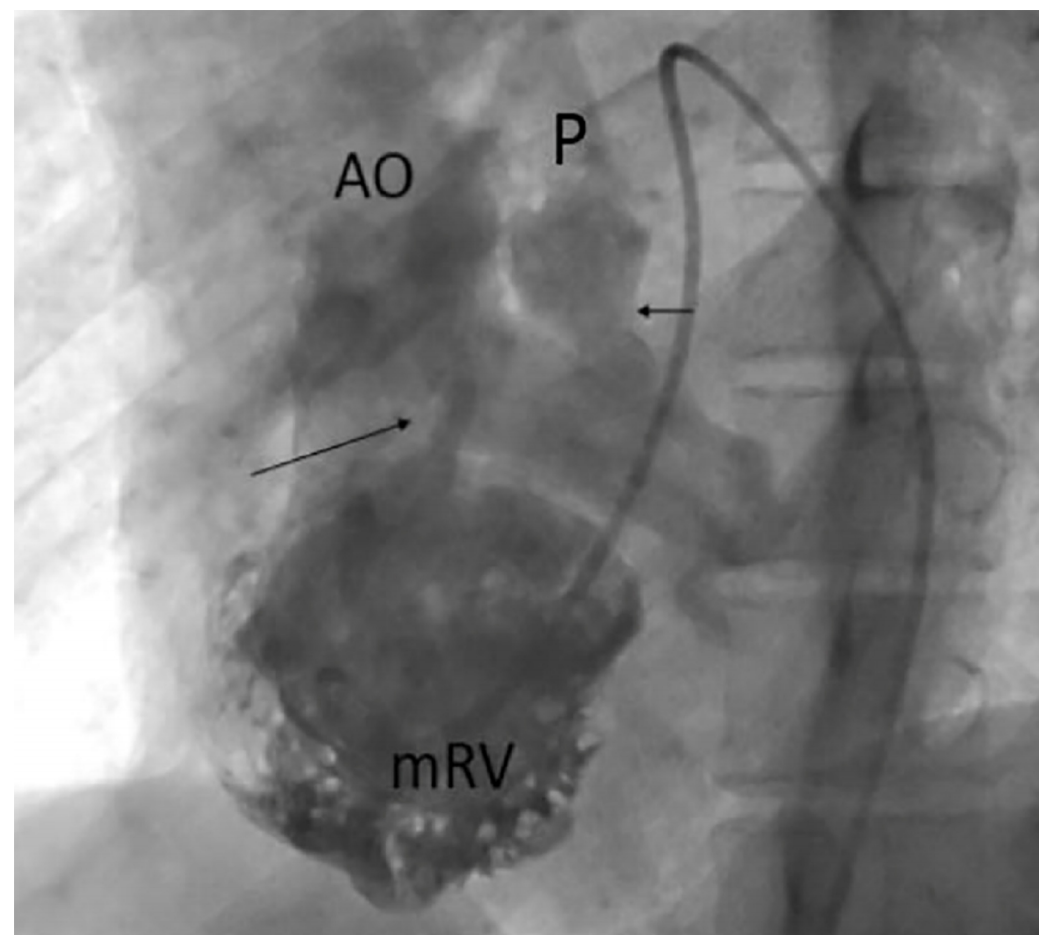

Figure 2. Preoperative cardiac catheterization of a CCTGA and Situs Inversus patient showed the anteriorly placed aorta arising from the morphologic right ventricle and the posteriorly placed pulmonary artery arising from the morphologic left ventricle and in association with ventricular septal defect (long arrow), pulmonary stenosis (short arrow). $\mathrm{AO}=$ Aort, $\mathrm{P}=$ Pulmonary artery, $\mathrm{mRV}=$ morphologic right ventricle.

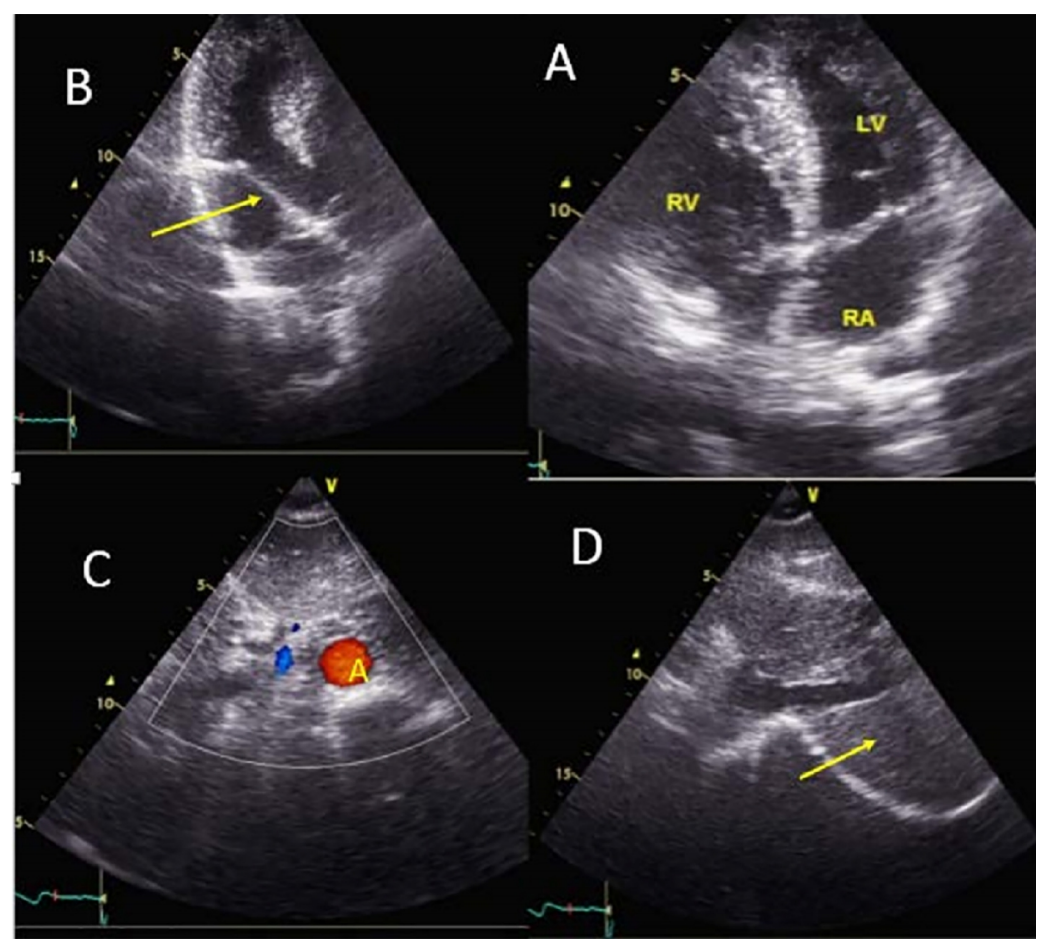

Figure 3. Transesophageal echocardiography (TEE). A- four-chamber view showed discordance atrioventricular connection and morphologic Left atrium in the right side is connected to the morphologic right ventricle, Morphologic right atrium in the left side is connected to the morphologic left ventricle, $L V=l e f t$ atrium, $R A=$ right atrium, $\mathrm{RV}=$ right ventricle, B- VSD (arrow), C- The aorta arises in anterior and the right side of the pulmonary trunk. $\mathrm{A}=$ aort, D- Liver (narrow) is on the left, revealing Situs Inversus. 


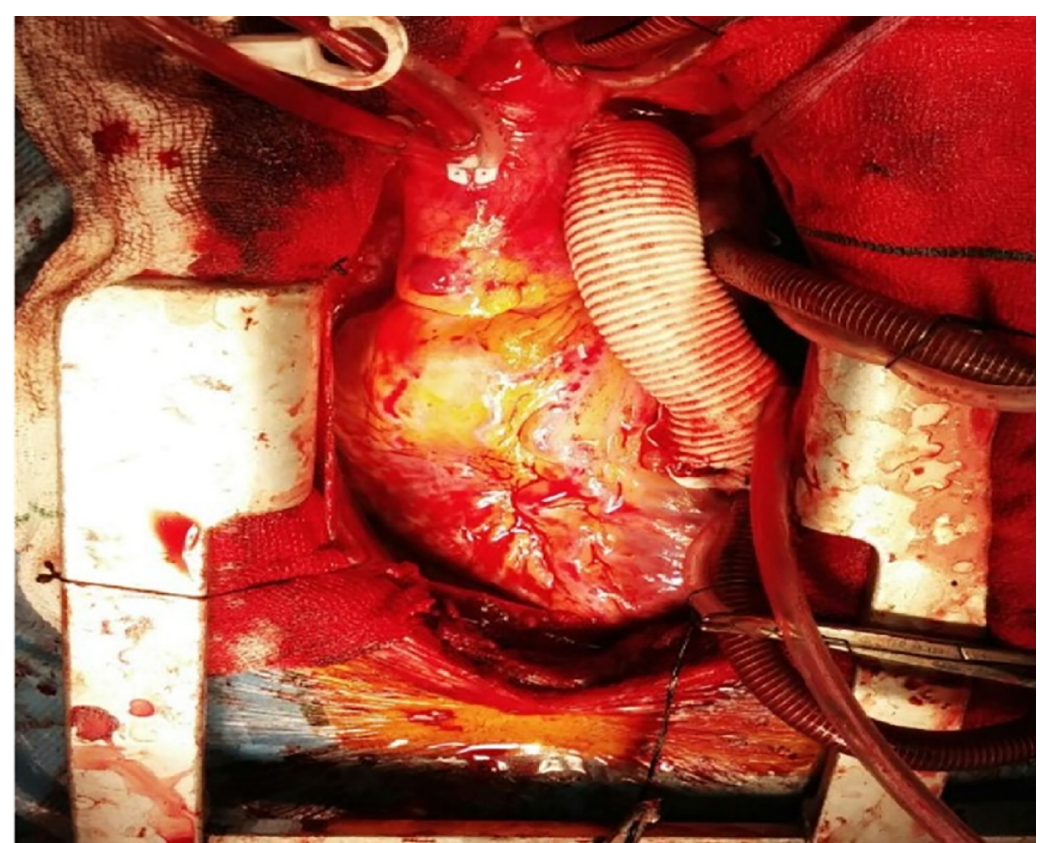

Figure 4. Placing an external valved conduit from morphologic left ventricle to pulmonary trunk.

\subsection{Follow-up}

Echocardiography three weeks after operation, demonstrated normal size $\mathrm{mLV}$, with normal left ventricular ejection fraction (LVEF) calculated at 50-55\%. There was a mild regurgitation of the left AV valve. Visible residual VSD and significant PS was not seen. Twenty days after the operation, he was slowly recovering and ventilated with low pressures and hemoptysis decreased. He was discharged thirty five days after operation in a good general condition.

\subsection{Ethics of case report}

Written informed consent was obtained from the patient for publication of this case report and any accompanying images. A copy of the written consent is available for review by the Editor-in-Chief of this journal.

\section{Discussion}

The CCTGA is a rare congenital cardiac anomaly which occurs in less than one percent of all forms of congenital heart disease (1-3). Most cases are Situs Solitus, therefore, the combination of CCTGA and situs inversus with levocardia are extremely rare defects, especially in adulthood (5). Echocardiogram of our patient showed the CCTGA and situs inversus with levocardia. Kukreti and colleagues (6) described a similar case of a 30 -year-old male with situs inversus with levocardia and Congenitally Corrected Transposition of Great Vessels but he associated with rheumatic systemic AV valve stenosis and regurgitation. Coexisting anomalies in CCTGA are seen in eighty percent of cases, and the majority of them have a VSD or PS or both. $(4,7)$ Our patient also had both of these associated anomalies. Allwork and colleagues (8) reported thirty two autopsy cases of CCTGA of which in twenty nine cases, the heart was in situs solitus and in three it was in situs inversus. Also, the most common associated defects in patients were tricuspid valve (TV) anomalies, which occurred in ninety one percent of cases, VSD in seventy eight percent and pulmonary outflow tract obstruction in forty four percent. Indications for surgery in this anomaly are directly related to the severity of the associated anomalies (3). The management of this defect is required to have a good knowledge of anatomy, physiology, and natural history (2). Surgical repair of CCTGA includes classical (physiologic) or anatomic repair. The classical surgical approach to CCTGA has been repairing the associated defects such as VSD, tricuspid regurgitation or stenosis, and pulmonary valve abnormalities. This approach leaves the $\mathrm{mRV}$ as the systemic ventricle and the morphologically right AV valve (tricuspid) as the systemic AV valve. So, because of concern about the long-term function of the mRV and the systemic AV valve, some reports suggest anatomic repair, which includes Senning and Arterial Switch Procedure (Double Switch) and Senning plus Rastelli Procedure (9). A Review study by Alghamdi and colleagues (3) between 1992 and 2000 revealed that the anatomic repair (Rastelli Procedure) was associated with the lowest incidence of postoperative complications and favorable to early mortality compared with the physiologic repair. Some studies demonstrated that anatomic corrective surgery is feasible in children but in adults, mortality is high, so this operation is not 
suggested (2). In some patients with CCTGA, the best surgical option is physiologic repair, for example dextrocardia, small atrium, or inlet ventricular septal defect features or other complex conditions (9). Although the best surgical procedure, in cases of complicated CCTGA remains controversial a number of studies have confirmed that age is one of the most important factors for selecting surgical procedure. Devaney and colleagues (10) showed that anatomic repair with a combined senning and arterial switch operation had a favorable outcome in patients with CCTGA. In these series, the procedure was unsuccessful in two patients who underwent banding at an older age (12 and 14 years). Thus, the anatomic repair is not always suitable for older patients. Our patient was an adult, and his condition was very complicated, therefore, he underwent physiologic repair.

\section{Conclusions}

We introduced a rare case of CCTGA and situs inversus with levocardia of which an adult patient underwent physiologic repair. In addition, international papers have published very few cases of adult patients with CCTGA with situs inversus and other associated defects, so management of these patients; particularly complicated cases remain controversial.

\section{Acknowledgments:}

We wish to thank the cardiac surgery department of Imam Reza Hospital for their support.

\section{Conflict of Interest:}

There is no conflict of interest to be declared.

Authors' contributions:

All authors contributed to this project and article equally. All authors read and approved the final manuscript.

\section{References:}

1) Connelly MS, Liu PP, Williams WG, Webb GD, Robertson P, McLaughlin PR. Congenitally corrected transposition of the great arteries in the adult: functional status and complications. J Am Coll Cardiol. 1996; 27(5): 1238-43. doi: 10.1016/0735-1097(95)00567-6. PMID: 8609349.

2) Kilner PJ, Geva T, Kaemmerer H, Trindade PT, Schwitter J, Webb GD. Recommendations for cardiovascular magnetic resonance in adults with congenital heart disease from the respective working groups of the European Society of Cardiology. Eur Heart J. 2010; 31(7): 794-805. doi: 10.1093/eurheartj/ehp586. PMID: 20067914, PMCID: PMC2848324.

3) Graf M, Zaczkiewicz M, Torzewski J, Zimmermann O. Atrial fibrillation-induced cardiac shock: first manifestation of a congenitally corrected transposition of the great arteries in a 45 -year-old man. Case reports in cardiology. 2012; 2012: 4. doi: 10.1155/2012/126764.

4) Alghamdi AA, McCrindle BW, Van Arsdell GS. Physiologic versus anatomic repair of congenitally corrected transposition of the great arteries: meta-analysis of individual patient data. Ann Thorac Surg. 2006; 81(4): 1529-35. doi: 10.1016/j.athoracsur.2005.09.035. PMID: 16564320.

5) Mah K, Friedberg MK. Congenitally Corrected Transposition of the Great Arteries Situs Solitus or Inversus. Circulation: Cardiovascular Imaging. 2014; 7(5): 849-51. doi: 10.1161/circimaging.114.002277.

6) Kukreti BB, Ramakrishnan S, Bhargava B. Situs inversus with levocardia and congenitally corrected transposition of great vessels with rheumatic tricuspid valve stenosis and regurgitation. Heart Views. 2011; 12(4): 178-80. doi: 10.4103/1995-705X.90908. PMID: 22574246, PMCID: PMC3345156.

7) Kantarci M, Koplay M, Bayraktutan U, Gundogdu F, Ceviz N. Congenitally corrected transposition of the great arteries: MDCT angiography findings and interpretation of complex coronary anatomy. The international journal of cardiovascular imaging. 2007; 23(3): 405-10. doi: 10.1007/s10554-006-9156-x.

8) Allwork SP, Bentall HH, Becker AE, Cameron H, Gerlis LM, Wilkinson JL, et al. Congenitally corrected transposition of the great arteries: morphologic study of 32 cases. Am J Cardiol. 1976; 38(7): 910-23. doi: 10.1016/0002-9149(76)90804-3. PMID: 998526.

9) Karl TR. The role of the Fontan operation in the treatment of congenitally corrected transposition of the great arteries. Ann Pediatr Cardiol. 2011; 4(2): 103-10. doi: 10.4103/0974-2069.84634. PMID: 21976866, PMCID: PMC3180964.

10) Devaney EJ, Charpie JR, Ohye RG, Bove EL. Combined arterial switch and Senning operation for congenitally corrected transposition of the great arteries: patient selection and intermediate results. J Thorac Cardiovasc Surg. 2003; 125(3): 500-7. doi: 10.1067/mtc.2003.158. PMID: 12658191. 